\title{
CONTRATRANSFERÊNCIA E ENQUADRE PSICANAlítico EM Pierre FÉdidA
}

\author{
Helena Maria Melo Dias* \\ Manoel Tosta Berlinck ${ }^{* *}$
}

\section{Resumo}

Objetivamos sublinhar o fecundo e complexo pensamento de Fédida sobre a técnica psicanalítica, tratando da articulação das noçôes de contratransferência e de enquadre no dispositivo clínico psicanalítico. Sua concepção de contratransferência tem como modelo implícito a relação fictícia mãe-bebê, na qual a mãe é uma receptora capaz de ressonância com o estado psíquico da criança para ativação da linguagem e consequente alívio de seu sofrimento. Ele identifica na contratransferência uma função que regula a "experiência intersubjetiva” analista-paciente e tem a função de para-excitação, que se rege em nível pré-consciente capaz de nomeação. Isso é o que sustenta o enquadre analítico como espaço de potência, que engendra a situação analítica.

Destacamos o estilo evocativo da escrita de Fédida, que mobiliza o pensar e o insigth, próprio da metapsicologia freudiana. Desse modo, suas elaboraçóes contribuem, significativamente, para maior compreensão da psicoterapia psicanalítica.

Palavras-chave: técnica psicanalítica; contratransferência; enquadre; situação analítica.

\section{ABSTRACT}

Countertransference and the psychoanalytic setting in Pierre Fédida

The objective here is to discuss Pierre Fedida's broad and complex thinking regarding psychoanalytic technique through an articulation of the notions of countertransference and setting

* Psicanalista. Doutora em Psicologia Clínica pela Pontifícia Universidade Católica de São Paulo (PUC-SP). Professora Adjunta da Universidade do Estado do Pará.

** Sociólogo, psicanalista, Ph.D. pela Cornell University, Ithaca, N.Y., USA. Professor da Universidade Estadual de Campinas (UNICAMP, Campinas, SP/Br.). 
in the psychoanalytic clinic. The model implicit in Fedida's conception of countertransference is the fictitious mother-baby relationship, where the mother is a receiver able to be in resonance with the child's psychic state. As a result, she can activate the baby's language and consequently alleviate its suffering. Fedida sees in the countertransference a function that regulates the "intersubjective experience" between analyst and patient and has a function of para-excitation, governed at a pre-conscious level of naming. This is what sustains the analytic setting as a space of potency that engenders an analytic situation. We also call attention to the evocative style of Fedida's writing, as it mobilizes thinking and insight proper to Freudian metapsychology. In short, his work has contributed significantly to a broader understanding of psychoanalytic psychotherapy.

Keywords: psychoanalytic technique; countertransference; setting; analytic situation.

O saber é necessário ao médico para que este se torne terapeuta, mas ele só será terapeuta se junto a ele se dispuser a fala do doente - fala em sofrimento de seu desejo de falar.

(Pierre Fédida, 1991)

Essa epígrafe de Pierre Fédida evocou-nos várias questóes, dentre estas: abertura do saber médico à escuta da fala do doente, como próprio daquele que quer se tornar terapeuta. Isto requer uma disposição deste para tomar o paciente em tratamento, bem como o desejo de falar do paciente como meio de transferência. Neste sentido, serão essas as condiçôes básicas para o encontro terapêutico? $\mathrm{Na}$ especificidade da psicoterapia psicanalítica, o desejo de falar do paciente deve encontrar, na escuta do analista, uma possibilidade de germinação e de construção, tal qual a interlocução no sonho, como concebido por Freud. É desta perspectiva que o trabalho de análise tem como paradigma o trabalho do sonho?

As questôes acima suscitadas serão trabalhadas no decorrer deste texto. Neste momento, o que queremos destacar, com a citação em epígrafe, é o estilo evocativo da escrita de Pierre Fédida. O estilo da inventividade do pensamento metapsicológico freudiano, que este autor sustenta, é ressaltado por outros, como Daniel Delouya e Manoel Berlinck. Berlinck (2002) considera que a leitura da obra de Fédida evoca a livre associação. E, de modo surpreendente, faz-nos pensar a clínica psicanalítica. Para ele, a escrita transparente, elucidativa, fecunda e complexa de Fédida tem um efeito psicoterapêutico e coloca o analista na comunidade psicanalítica. Entendemos o efeito psicoterapêutico dessa escrita no sentido de ampliação da atividade psíquica do leitor, com as evocaçóes que seu texto produz

Psic. Clin., Rio De JANEIRo, vol.23, N.2, P.22I - 23I, $201 \mathrm{I}$ 
e que mobiliza o pensar e o insight. Por isso, Daniel Delouya (1999), na introdução do livro Depressão, de Fédida, observa:

este gênero de pensamento jamais cede à coerência articulada de um raciocínio, mas se abre constantemente para as imagens e para as figuras do vivido das palavras que utiliza. Eis o modo da poesia e da fenomenologia entremearem o tecido metapsicológico temperando o rigor com que o autor se fia às buscas e aos questionamentos da feiticeira freudiana (Delouya, 1999: 10).

$\mathrm{Na}$ leitura da obra de Fédida, somos capturados pelo enlace transferencial de sua escrita, que tem como referência uma profunda sensibilidade clínica articulada a um vasto conhecimento dos estudos sobre a psicopatologia. Isto nos faz enfocar a compreensão deste autor sobre a metapsicologia da técnica psicanalítica, na qual destacamos, neste artigo, a articulação entre contratransferência e enquadre analítico.

\section{O SENTIDO DE CONTRATRANSFERÊNCIA}

$\mathrm{Na}$ tese que defendemos sobre a relevância da contratransferência como dispositivo clínico psicanalítico, sustentamos que a concepção de Fédida amplia e aprofunda a compreensão deste conceito. Esta concepção refere à metapsicologia dos processos psíquicos do analista e náo à pessoa do analista (Dias, 2007). Para ele, "é digno de nota que a despeito da abundante literatura psicanalítica que trata da concep̧̧ẫo de contratransferência muito pouco desta dá lugar a um verdadeiro projeto metapsicológico" (Fédida, 1992: 189; trad. livre). Afirma que a maior parte dos autores que tratam dessa questáo entendem o tratamento psicanalítico - de modo equivocado - como uma relação analista-paciente, ou seja, uma relação interpessoal; e não é disso que se trata no processo analítico, uma vez que a transferência náo tem como destinatário a pessoa do analista, mas sim o objeto interno alucinatório da transferência, a partir do que o analista interpreta essa dinâmica psíquica. Entende que "na transferência, a alucinação negativa tem como função tornar possível a 'absenteização' da pessoa em presença, já que 'a apresentação da presença evita, por assim dizer, a presentação da pessoa”" (Fédida, 1996: 34). No entanto, depreende nessa concepção, que enfatiza a relação analista-analisando, um sentido que dá ênfase a um modelo fictício mãe-bebê correlativo ao analistapaciente, capaz de ressonância e continência ao estado de angústia do paciente e apropriado à linguagem no tratamento.

Assim, a manifestação contratransferencial, como algo do erótico do analista que deve ser dominado, equivale a um dispositivo clínico importante para o trata- 
mento, pois corresponde à capacidade do analista de observar e de compreender suas próprias reaçóes íntimas quanto àquilo que o paciente lhe comunica. $\mathrm{Ou}$ seja: as imagens que se formam no analista com sua escuta ao paciente; o desenho interno da fala, o que isso lhe informa dessa clínica.

Eliana Borges Leite (2001), em seu livro A figura na clínica psicanalítica, defende a tese de que

a escuta por imagens tem capacidade de recepção da "coisidade sensorial das palavras", dimensão estética anterior à formalização sintática e semântica que se dá na comunicação, da qual a linguagem se distancia quando ingressa no regime da significação e da discursividade. O retorno às imagens e sua colocação em figuras realiza um trabalho de desalienação da linguagem de sua função convencional e restaura sua capacidade de apresentar o desenho interno da fala. Como no sonho, restitui às palavras sua virtualidade e sua mobilidade, permitindo que se instale a atividade de renovaçáo, ou antes, de engendramento constante da própria linguagem, que confere à escuta na análise sua especificidade (Leite, 2001: 19-20).

No livro dos sonhos, peça central de sua obra, Freud (1987 [1900]) discorre sobre esse trabalho de desalienação da linguagem da sua função convencional, propondo os dois teoremas que se tornam os pilares básicos da técnica psicanalítica: um, "quando se abandonam as representaçóes-meta conscientes, as representaçóesmetaocultas assumem o controle do fluxo de representaçóes"; o outro, é que "as associaçôes superficiais são apenas substitutos, por deslocamento, de associaçóes mais profundas e suprimidas" (Freud, 1987[1900]: 487). Justamente, é esse trabalho de desalienação da linguagem que permite o processo transferencial regressivo: "o pensamento se transforma em imagens visuais e fala” (Freud, 1987 [1900]: 490).

Fédida (1988) - num estilo bem freudiano - sustenta em toda sua obra o sonho como paradigma da clínica psicanalítica, pois, para ele, o sonho é o paradigma da teoria do trabalho do inconsciente, do sexual, do pensamento, da transferência. Assim, relembra aos analistas que:

se Freud tem o cuidado de lembrar de ponta a ponta na sua obra que o sonho é, de certa forma, o paradigma teórico da técnica analítica é porque "a associabilidade do sonho, seu caráter incompreensível para o próprio sonhador sáo os correlatos da mais secreta intimidade da fala". Por isso, "o estranho é a língua fundamental da intimidade do sonho e da fala da qual ele é fonte" (Fédida, 1988: 81).

Psic. Clin., Rio De JANEIRo, vol.23, N.2, P.22I - 23I, $201 \mathrm{I}$ 
No seu entender, "o próprio do que chamamos transferência está em constituir em si um fenômeno Unheimlich, pelo seu desencadeamento e pela potência psicótica (alucinatória) dos processos ativados" (Fédida, 1988: 91). Nesse sentido, com base nos estudos do mestre de Viena, Fédida (1996) enfatiza:

O fenômeno da transferência nunca deixa de espantar, constatava Freud. E em 1938, no Compêndio, ele convida ainda mais uma vez os analistas a não perderem esse espanto: "É bem estranho que o analisado reencarne em seu analista uma personagem do passado". Náo duvidemos que aquele que não consegue mais se espantar com a estranheza da transferência já esqueceu ou negligenciou, há muito tempo, o sítio do estrangeiro e, com certeza, a virtude da linguagem, interlocutor da transferência (Fédida, 1996: 174).

Com base nesses estudos da situação analítica é que Fédida (1989: 100) critica os processos de intelectualizaçáo teórica do analista, bem como o movimento do empirismo da espontaneidade, "que inevitavelmente leva o analista a fazer depender a eficácia de suas intervençóes de investimento narcisista de sua própria pessoa". Isto é feito por meio do incremento de "presença" da pessoa, que anula a presença do infantil estrangeiro e, desse modo, o infantil é recusado em proveito de uma historicidade da infância. Negligenciar o que se fala em benefício da atenção ao que acontece "é a forma segundo a qual podemos conceber a recusa do infantil pelos próprios analistas, pois, neste caso, não reconhecemos a palavra (parole) carregando em si mesma a regressão tópica (os traços mnêmicos)". (Fédida, 1989: 103).

A familiarização da fala aumenta as representaçôes conscientes do pensamento, reforça o império e o domínio do representável em detrimento do figurável e, por fim, diminui, na mesma medida, a esperança da linguagem em suposto benefício do imaginário eu. Em consequência, a familiaridade desinstaura a situação analítica regida pela associação livre e a atenção equiflutuante em prol da relação interpessoal. Assim, Fédida é incisivo quanto à responsabilidade do analista com respeito à fala do paciente que concerne, portanto, à instauração pelo analista da situação analítica em psicoterapia. "É desta responsabilidade que procede uma resposta, a qual é dada pelo engajamento de responsabilidade implicado na instauraçáo da situação analítica" (Fédida, 1989: 115).

Quer dizer, a condição de instauração da situação analítica está referida à condiçâo de linguagem e disso resulta que, na técnica analítica, "o analista deve, portanto, permanecer impenetrável (undurchsichtig) e, 'como superfície de espelho, não mostrar nada além do que lhe foi mostrado"' (Fédida, 1991: 207). A referência a essa proposição freudiana torna possível a especificação de que "o que nos faz 
terapeutas é a existência da regra fundamental em nosso pensamento, assim como de tudo o que se passa entre nós e o paciente como desvios em relação a essa regra ideal" (Fédida, 1988: 31). Desse modo, é por meio contratransferencial que o analista identifica esses desvios da regra fundamental.

Na interpretação de Fédida (1989), é esta a vantagem de considerar a atividade psíquica do analista como a de um "aparelho" sensível, suposto constantemente discriminador de suas mudanças de "regime" e, assim, autoinformativo das mínimas modificaçóes sobrevindas no movimento psíquico do paciente. Para tanto, torna-se imprescindível que o analista depure esse "aparelho" sensível por meio de sua própria análise. Esta exigência de que o analista se submeta ao processo analítico para desvendar sua própria dinâmica psicopatológica é a única base confiável para que o analista compreenda o processo psicopatológico de seu paciente. $\mathrm{Na}$ proposição de Fédida

poder-se-ia então conceber que o que nos é analiticamente conhecível de nós mesmos e dos outros analistas - e o que nos é, nestas condiçôes, metapsicologicamente pensável como processos psíquicos da atividade de analista é $o$ psicopatológico na medida em que caracteriza estes processos. Isto é ainda mais provável já que cada paciente no seu tratamento faz vir à tona e reativa nossa psicopatologia pessoal (Fédida, 1989: 119).

Este resto não resolvido potencializa a análise, na medida em que evoca no analista o sitio do estrangeiro. No dizer de Fédida (1989: 119) "certamente não seria falso ousar pretender que os analistas são analistas e continuam sendo porque continuam a engajar com seus pacientes - transferencialmente - este 'resto não resolvido’ de sua própria análise".

Em As múltiplas faces de Eros: uma exploração psicoanalítica da sexualidade humana, Joyce McDougall (1997) trata esse "resto não resolvido" e seus efeitos contratransferenciais, que foram muito valiosos na análise de Marie-Josée - sua paciente -, dizendo:

minha surdez contratransferencial, juntamente com minhas fantasias recalcadas, tinham funcionado como uma tela opaca, impedindo que a "luz" analítica iluminasse não somente a vida sexual adulta insatisfatória de Marie-Josée, mas também um elemento fantasístico predominante de sua frigidez parcial: a saber, seus desejos homossexuais não-reconhecidos" (McDougall, 1997: 32).

Interessante, pois essa interpretação originou-se de "um sonho contratransferencial" de McDougall. Após a análise desse sonho, a analista deu-se conta de quanto 
sua paciente - resto diurno - mobilizava esse resto náo resolvido, o qual emergiu livremente no sonho e possibilitou o desenrolar da análise de Marie-Josée.

Pensamos ser esse o lugar de ressonância em que consiste o dispositivo da contratransferência. Este permite, quando pode ser reinstaurado, que o analista recupere sua condição como estranho/estrangeiro, cujo silêncio em sua negatividade produz a dessignificação e oferece à fala uma recepção em sua máxima potência de constituir a linguagem como portadora do tempo e da memória do infantil. O modelo do sonho, táo caro a Freud, orienta esta formulaçáo como paradigma teórico da técnica e cujo valor Fédida nunca deixa de sublinhar. O sonho, em sua estranheza e intimidade, é o guardiāo da memória adormecida. McDougall nos traz essa memória que, adormecida, se deixa mobilizar pelos restos diurnos oriundos da análise de Marie-Josée. Nesse sentido, a contratransferência, em sua função de recepção e transformação das transferências, permite ao analista ser o guardião do sítio em que se torna possível a construção da linguagem na análise.

Pensamos que essa função de recepção e possibilidade de transformaçôes das transferências - tanto do analisando quanto do analista - seja garantida pelo estabelecimento e manutenção do enquadre analítico.

\section{ENQUADRE ANALÍTICO}

O enquadre está referido ao estabelecimento da regra fundamental da psicanálise, na qual o paciente deve falar tudo que lhe vier à cabeça, sem censura, orientado por um pensamento livre associativo. Já o analista deve manter uma escuta movida por uma atençáo flutuante à fala do paciente. A regra estabelece um compromisso do analista e do analisando com o enquadre no processo analítico. Como diz Berlinck (2000: 260): “a regra é fundamental porque funda, constitui, dá início ao tratamento e, por isso, precisa ser explicitamente declinada pelo psicanalista e formalmente aceita pelo analisando". Acrescentamos que a regra fundamental não só funda como mantém a especificidade da situação psicanalítica.

Em "A angústia da contratransferência ou o sinistro (a inquietante estranheza) da transferência”, Fédida (1988) especifica sua concepçáo de contratransferência, argumentando que:

O modelo implícito da contratransferência é o de uma relação fictícia mãefilho, onde a mãe se faz receptora do que acontece com seu filho. Ela experimenta uma angústia que a desperta para o perigo, que aumenta a acuidade da percepção de si mesma e do filho; restitui a este, através de palavras e de gestos 
adequados, a significação distinta do que ele experimenta, portanto, sem confusão com a sua própria. Dito de outra forma, a angústia contratransferencial do analista poderia ser, idealmente, a de uma mãe capaz de ressonância com o estado da criança, de continência das energias desta angústia, de metabolização e de metaforização dos afetos confundidos que tendem a transbordar na criança. É, portanto, o modelo da relação mãe-filho que regula a função de experiência intersubjetiva da contratransferência e faz desta um dispositivo pré-consciente apropriado para dar, na linguagem, ressonância dos diferentes estados vivenciados pelo paciente. Nestas condiçôes, a angústia contratransferencial não aparece apenas como uma "resposta", mas sim como um momento crítico da atenção e, assim sendo, como instante analítico de constituição da interpretação (Fédida, 1988: 74-75).

Esse pensamento de Fédida (1988) sobre a angústia da contratransferência nos parece fecundo. A angústia, como sinal de alarme - tal como formulada por Freud em "Inibiçóes, sintoma e ansiedade" (1987 [1926]) -, evocada na contratransferência, constitui-se um momento crítico da atenção do analista, momento constitutivo de interpretação, recurso do analista para que a análise da transferência do paciente possa transitar por meio da linguagem, caso se mantenha a situação clínica. Em sua argumentação, Fédida esclarece como modelo uma relação fictícia mãe-filho por reconhecer, na contratransferência, uma função que regula a "experiência intersubjetiva" sem se confundir com os afetos que transbordam na criança-paciente, função de paraexcitação, que se rege em nível pré-consciente capaz de nomeação. Para tanto, "se a escuta do analista consegue ser, no silêncio, atividade de linguagem e ativação do figurável, a fala do analisando encontra pouco a pouco as condiçóes de seu próprio silêncio associativo" (Fédida, 1988: 78).

Em $O$ sitio do estrangeiro, Fédida (1996) especifica o sentido que emprega para designar o materno na clínica psicanalítica.

$\mathrm{Na}$ perspectiva em que nos situamos, o materno é, sem dúvida, muito mais associado na situação analítica à percepção pré-consciente dos dados sensoriais da presença em pessoa do analista, assim como a ambientação da sessão: ele constitui o material corporal dessa presença, cuja importância tradicional nas menores variaçóes qualitativas na relação com o paciente não pode ser ignorada. Mas embora esse materno - que talvez não esteja bem nomeado assim - crie as condiçôes temporais (quase pré-sensoriais) de troca imaginária $d a$ transferência, ele não poderia ser confundido com a própria transferência ou, pelo menos, com o movimento de sua regressáo tópica inconsciente (Fédida, 1988: 151).

Psic. Clin., Rio De JANEIRO, vol.23, N.2, P.22I - 23I, $201 \mathrm{I}$ 
Consideramos importante essa distinção entre a troca imaginária $d a$ transferência e o movimento de sua regressão tópica inconsciente, porque esse processo regressivo-transferencial remete à singularidade do sujeito, ele e seu interlocutor, tal como no sonho.

Essa referência ao materno diz respeito às condiçôes de análise que envolve a ambientação da sessão. O material corporal dessa presença acolhedora corresponde ao que se denomina enquadre na situação analítica, pois, para Fédida (1996), o enquadre é um espaço de potência que engendra a situação analítica. Situação analítica entendida na sua dinâmica de instauração, desinstauração, reinstauração - dinâmica própria da clínica psicanalítica. Nesse sentido, este autor formula sua concepção de enquadre:

a ideia de que o enquadre analítico - engendrado pela regra fundamental - corresponde a um valor de ordem semiótica-jurídica de amplo alcance axiomático, que não exige mais do que poucas palavras para ser significado no começo de um tratamento analítico. A ficcionalidade deste valor assim compreendido é certamente intrínseca à sua proposiçāo lógica e às modalidades de sua enunciação. Será dito que a sessäo implica a unidade de lugar a portas fechadas, que este lugar é o de um tempo a uma só vez estável, regular, frequente e contínuo (como exige a fala em presença), que a análise implica em dois, cada um em sua posiçáo sem variar, excluído então o terceiro sob qualquer forma que seja aí compreendido sob esta forma paradoxal do analista em pessoa (Fédida, 1996: 67).

Entendemos ser uma forma paradoxal do analista em pessoa, porque ao mesmo tempo que imaginariamente o paciente pensa dirigir-se a esta pessoa - e, para Fédida, isso é necessário, pois "a distinção dos corpos antecipa a distância da fala e de seu sonho" (Fédida, 1996: 68) -, também é pelo silêncio do analista que se instaura a situaçáo analítica. Ou seja, é pela não-presença em pessoa - no dizer de Freud, pela neutralidade - que se presentifica o estrangeiro - inatual/atual da infância. Por isso, em sua elaboraçáo sobre a clínica psicanalítica, concebe que:

a situaçáo analítica pode ser descrita como um lugar, caso estejamos de acordo para reconhecer-lhe uma organização cênica [...] como uma situaçáo indicaria primeiramente que se trata de um sitio, e que este sítio é o estrangeiro, que nela descobre a fala quando esta se surpreende escutando aquilo que diz. (Fédida, 1991: 61).

Como colocamos anteriormente, Fédida sustenta em toda sua obra o sonho como paradigma da clínica e técnica psicanalítica. Para ele, o sonho é o paradigma 
da teoria do trabalho do inconsciente, do sexual, do pensamento, da transferência. Por isso, "o estranho é a língua fundamental da intimidade do sonho e da fala da qual ele é fonte" (Fédida, 1988: 81). Porque o caráter enigmático do sonho, como paradigma da técnica psicanalítica, fundamenta seu pensamento de que "o próprio do que chamamos transferência está em constituir em si um fenômeno Unheimlich, pelo seu desencadeamento e pela potência psicótica (alucinatória) dos processos ativados" (Fédida, 1988: 91).

Nesse sentido, com base nos estudos do mestre de Viena, Fédida (1996), como vimos, enfatiza o fenômeno da transferência como algo inapreensível, que nunca deixa de espantar, como constatava Freud - em 1938, no Compêndio, Freud convida ainda mais uma vez os analistas a não perderem esse espanto. "É bem estranho que o analisado reencarne em seu analista uma personagem do passado" diz Fédida. Observa que "aquele que não consegue mais se espantar com a estranheza da transferência já esqueceu ou negligenciou, há muito tempo, o sítio do estrangeiro e, com certeza, a virtude da linguagem, interlocutor da transferência" (Fédida, p. 174).

\section{ConsideraÇóEs finais}

O pensamento de Fédida sobre as diferentes perspectivas e funções que envolvem a contratransferência, entendendo que o enquadre, por engendrar a instauração da situação analítica, está referido ao estabelecimento da regra fundamental, estabelece que a condição da escuta analítica é a única base confiável para que o analista compreenda o psicopatológico de seu paciente. É nesse sentido que a contratransferência diz respeito à posiçáo de disjunção do analista para poder apreciar e interpretar essa dinâmica psicopatológica.

\section{REFERÊNCIAS}

Berlinck, M. T. (2000). Psicopatologia fundamental. São Paulo: Escuta.

Berlinck, M. T. (2002). Pierre Fédida (1932-2002). Retirado de: <http://www.gradiva. com.br/obit.htm>.

Delouya, D. (1999). Introdução à depressão, de Pierre Fédida. São Paulo: Escuta.

Dias, H. M.(2007). Contratransferência: um dispositivo clinico psicanalítico (Tese de Doutorado). Curso de Pós-Graduação em Psicologia Clínica. Pontifícia Universidade Católica de São Paulo.

Psic. Clin., Rio DE JANEIRO, vol.23, N.2, P.22I - 23I, $201 \mathrm{I}$ 
Fédida, P. (1988). Clínica psicanalítica: estudos. São Paulo: Escuta.

Fédida, P. (Org.). (1989). Comunicação e representação. São Paulo: Escuta.

Fédida, P. (1991). Nome, figura e linguagem. São Paulo: Escuta.

Fédida, P. (1992). crise et Contre-transfert. Paris: Presses Universitaires de France.

Fédida, P. (1996). O sitio do estrangeiro. São Paulo: Escuta.

Fédida, P. (1999). Depressão. São Paulo: Escuta.

Freud, S. (1900/1987). A interpretação dos sonhos. Obras completas, ESB, vs. IV eV. Rio de Janeiro: Imago.

Freud, S. (1926 [1925]/1987). Inibições, sintomas e ansiedade. Obras completas, ESB, v. XX. Rio de Janeiro: Imago.

Leite, E. B. P. (2001). A figura na clínica psicanalítica. São Paulo: Casa do Psicólogo.

McDoulgall, J. (1997). As múltiplas faces de Eros: uma exploração psicanalítica da sexualidade humana. (Trad. Pedro H. B. Rondon). São Paulo: Martins Fontes.

Recebido em 30 de julho de 2011 Aceito para publicação em 10 de agosto de 2011 